\section{Treatment of Abortion}

SIR,-Dr. J. McD. Corston and Mr. John Stallworthy (July 19 , p. 89) are to be congratulated on the low mortality of $0.17 \%$ in their series of 600 abortions treated by surgical evacuation of the uterus. Their results at least question the validity of the generalization that the mortality among cases of abortion treated actively is twice that among those treated conservatively. Studdiford (1939), not using chemotherapy, did not find any significant difference between the results in 1,248 cases treated actively from 1934 to 1937 and those of a control series of 7,184 cases treated conservatively from 1920-33.

In the North Middlesex County Hospital surgical evacuation of the uterus is the general rule. But in frankly septic cases not manifesting general peritonitis necessitating immediate laparotomy one of two courses is followed, depending upon the clinician in charge. In each a vaginal swab is taken for culture. Thereafter the uterus is evacuated immediately, drainage is established by a catheter, through which glycerin is introduced by a modified Hobbs' (1927) technique, and chemotherapy given as indicated by the bacteriological findings. Or a sulphonamide is administered and evacuation is postponed until the bacteriological report is available, when if haemolytic streptococci are present evacuation is not undertaken until the temperature has been normal for three or four days, while in the absence of haemolytic streptococci evacuation may be undertaken in febrile patients but is frequently postponed until the patient is afebrile.

In 1945 the M.R.C. Classification of Diseases was adopted in the hospital. Our abortion figures for that year (those for 1946 are not yet available) are comparable to those of the Oxford writers. Threatened, spontaneous complete, missed abortions, and one incomplete abortion in which the uterus was not evacuated (vide infra) have been excluded. During the year 480 cases of inevitable, incomplete, and septic abortions were treated along the lines indicated. In addition, five of them had laparotomy performed because of peritonitis. One patient died-a mortality of $0.2 \%$.

Fatal case.-Progressed satisfactorily for four days after evacuation of uterus, when vomiting, accompanied by renal tenderness, set in followed by oliguria, drowsiness, coma, and death nine days after operation. Before admission had visited an abortionist on six occasions. P.M. (coroner) oedema of the brain and subacute nephritis.

Among the cases excluded, as indicated, two patients died. Brief details of these are given lest it should be thought that the selection in the caser presented has been prejudiced. In neither case was there operative interference.

(a) Primigravida, aged 20, admitted with auricular fibrillation when 20 weeks pregnant. Spontaneous complete abortion. Steady deterioration. Died ten days later.

(b) Primigravida, aged 35, admitted moribund from septicaemia. Aborted foetus but not placenta. No haemorrhage. Died six hours after admission. $\mathrm{Cl}$. welchii in blood culture and in foetal tissues.

Prompt evacuation of the uterus is certainly more convenient for the patient. It ensures that the abortion is completed. It shortens her immediate illness and stay in hospital. Perhaps larger series will be published showing the results obtained under modern conditions. But if conservative treatment proves to be significantly safer, then many more hospital beds for the treatment of abortion will be required.

Unlike the authors I do not operate early on patients with severe haemorrhage. Ergometrine $0.5 \mathrm{mg}$. is given intramuscularly to arrest it, and repeated in one hour, two hours, and four-hourly during the period of resuscitation. Only exceptionally is the immediate additional removal of a piece of tissue from the cervical canal required. In the exsanguinated patient morphine gr. $\frac{1}{4}(16 \mathrm{mg}$.) and the first dose of ergometrine are given intravenously consecutively-this prevents the vomiting sometimes caused by the intravenous oxytocic. The haemorrhage arrested, she is rendered fit by blood transfusion for deliberate evacuation of the uterus.

Packing of the uterus I find almost unnecessary. Haemorrhage at evacuation is due to trauma which is preventable or can be controlled by sutures, incomplete evacuation of the uterine contents for which the remedy is obvious, or atony of the uterus. This last can be overcome by the avoidance of deep ether anaesthesia, by bimanual compression, or the use of an oxytocic. For rapid action of the oxytocic $\mathbf{P}$ usually have the anaesthetist give it intravenously during the evacuation. I should like to endorse the authors' closing statement that routine treatment is easy to prescribe, but on the nice decision of when to administer it may hang the balance between life and death. -I am, etc.,

London, N.18. Anthony W. Purdie.

Hobbs, J. R. (1927), British Medical Journal, ’2, 1223.
Studdiford, W. E. (1939). N.Y. St. J. Med., 39, 1274.

\section{Premature Birth at Sea}

SIR,-While I was acting as a ship's surgeon in 1946 a premature baby weighing only $2 \mathrm{lb} .7 \mathrm{oz}$. $(1.1 \mathrm{~kg}$.) was born at sea and has survived. Is this a record for the survival of an infant of this size born under these circumstances?

The mother was a primipara, aged 28 , who had been married nearly seven years. In 1944 she had a dilatafion and curettage, and later that year a cyst was removed from the left ovary and at the same time a round ligament suspension operation was performed. At this operation it was noticed that the right ovary was represented by a rudimentary seed, and the right tube was congenitally absent. The remaining portion of the left ovary, after the cyst had been removed, was, quite healthy. She became pregnant in 1946, and decided to return home to England from Australia.

When first seen on the ship on July 6, 1946, when her membranes ruptured, she stated that her L.M.P. was on Dec. 2, 1945. The patient commenced good labour pains on July 10, and during the evening of the next day was delivered of a live and fully developed baby girl weighing $2 \mathrm{lb} .7 \mathrm{oz}$.

At this time the ship was passing through the Indian Ocean, and the temperature in the ship's hospital was $96^{\circ} \mathrm{F}$. $\left(35.6^{\circ} \mathrm{C}\right.$.). The baby was wrapped in cotton-wool and placed in a cot. It was given $1 \mathrm{drachm}(3.5 \mathrm{ml}$.) of diluted breast milk by pipette every two hours for the first 6 days; this quantity was then increased from $2 \frac{1}{2} \mathrm{dr}$. $(8.5 \mathrm{ml}$.) to $5 \mathrm{dr}$. ( $(17.5 \mathrm{ml}$.) every two hours during the next 12 days. On the nineteenth day the baby could suck well and was given bottle feeds every three hours. For the first week of life the baby became very blue during feeds and caused some anxiety, but it quickly recovered on the administration of oxygen.

A letter received from the parents in January, 1947, stated the baby weighed over $15 \mathrm{lb}$. $(6.8 \mathrm{~kg}$.) and was progressing satisfactorily.-I am, etc.,

London, S.W.12.

D. E. Hayes.

\section{The Coroner's Court}

SIR,-We have read with some interest and much perturbation the procedure of the coroner's court in the case' of Dr. Clements, etc. We were under the impression that the duty of the coroner's court was to certify the cause of death only and not to try persons or pass a verdict as to their guilt.

Had Dr. Clements been alive he would have been condemned by this coroner's court, then been tried in court (which would have been biased against him by the verdict of the coroner's court), and then, thirdly, have to stand for trial again at the Old Bailey. Surely some mistake has occurred in this caseperhaps it is a sign of the times.-I am, etc.,

London, S.E.9.

\section{B. N. BLOoD.}

*** Our Medico-legal Correspondent writes: There was nothing new or improper in the procedure of the coroner's court in the Clements case. From time immemorial the coroner's jury has found named persons guilty of causing the death of the deceased. In fact, if they are to declare the cause of death it would be rather illogical to expect them not to do so. When a jury finds that a named person murdered the deceased or was guilty of his manslaughter, the coroner issues a warrant for the arrest of the person and, since the Act of 1926, commits him for trial as though he had been examined before magistrates. He is therefore not tried again until he comes up to assizes ; in fact, it is wrong to speak of the coroner's court "trying" him at all. Their finding is merely an expression of opinion incidental to their verdict on the cause of death, and biases the assize jury no more than would the order of justices committing him for trial. 